33. Standard genetic techniques and media were as described or referenced [L. C. DeVeaux, N. A. Hoagland, G. R. Smith, Genetics 130, 251 (1992); C. Grimm, J. Bähler, J. Kohli, ibid. 136, 41 (1994)].

34. D. E. Lea and C. A. Coulson, J. Genet. 49, 264 (1949).

35. We thank M. Roth, J. Ranish, and W. Wahls for advice in cloning; L. Clarke at the University of California, Santa Barbara, for the S. pombe genomic library; O. Fleck, P. Schär, and J. Kohli for making their data available before publication; $P$. Munz and J. Kohli for yeast strains; J. Kohli for discussion on mismatch correction; and S. Amundsen, P. Dabert, Y. F. Li, A. Taylor, J. Virgin, and W. Wahls for com- ments on the manuscript. Supported by NIH grant GM32194 (G.R.S.). The Biocomputing Resource Center at the Fred Hutchinson Cancer Research Center is supported by National Cancer Institute award P30 CA15704-20.

15 August 1994; accepted 14 December 1994

\title{
PER Protein Interactions and Temperature Compensation of a Circadian Clock in Drosophila
}

\author{
Zuoshi J. Huang, ${ }^{*}$ Kathryn D. Curtin, Michael Rosbash†
}

\begin{abstract}
The periods of circadian clocks are relatively temperature-insensitive. Indeed, the per ${ }^{L}$ mutation in the Drosophila melanogaster period gene, a central component of the clock, affects temperature compensation as well as period length. The per protein (PER) contains a dimerization domain (PAS) within which the per ${ }^{L}$ mutation is located. Amino acid substitutions at the per ${ }^{L}$ position rendered PER dimerization temperature-sensitive. In addition, another region of PER interacted with PAS, and the $p r^{L}$ mutation enhanced this putative intramolecular interaction, which may compete with PAS-PAS intermolecular interactions. Therefore, temperature compensation of circadian period in Drosophila may be due in part to temperature-independent PER activity, which is based on competition between inter- and intramolecular interactions with similar temperature coefficients.
\end{abstract}

Circadian rhythms, nearly ubiquitous in eukaryotes, are self-sustaining, have periods of approximately 24 hours, and can be entrained by environmental signals such as light. Unlike many physiological processes that are dependent on temperature, the period lengths of circadian clocks are nearly constant over a wide range of physiological temperatures (1). Such temperature compensation is crucial to the construction of a circadian clock; otherwise, the period length of the clock would fluctuate with ambient temperature and would be unreliable.

Although a number of hypotheses have been proposed (2), there is no experimental information on the molecular basis of temperature compensation in any system. However, mutations that compromise temperature compensation exist in the $D$. melanogaster period (per) gene and in the Neurospora frequency (fra) gene (3-5). For example, the period length of wild-type Drosophila varies less than 0.5 hour from $15^{\circ} \mathrm{C}$ to $30^{\circ} \mathrm{C}$, but the periods of $\operatorname{per}^{L}$ flies increase from about 27 hours to 33 hours over this temperature range, a change of more than $20 \%(4,6)$. Because both per and frq genes have been shown to be central components of circadian pacemakers (7), temperature compensation is likely to derive directly from intrinsic properties of

Howard Hughes Medical Institute, Brandeis University, Department of Biology, Waltham, MA 02254, USA.

*Present address: Department of Biology and Center for Cancer Research, Massachusetts Institute of Technology, Cambridge, MA 02139, USA.

tTo whom correspondence should be addressed. clock components or their interconnection.

The per mRNA and protein levels undergo robust circadian oscillations $(8-10)$, and there is a feedback loop in which PER affects the circadian transcription of its own gene $(8,11)$. PER contains a PAS domain, a protein dimerization motif present in several basic helix-loop-helix transcription factors $(12,13)$. The $\operatorname{per}^{L}$ mutation is a valine to aspartic acid missense mutation (14) in the PAS domain, which affects PAS-mediated PER-PER homodimerization in vitro (12) as well as period length and temperature compensation in vivo $(4,6)$.

To perform a structure-function analysis of the PER PAS domain, we reconstituted PER dimerization in a yeast two-hybrid system (Fig. 1) (15). Consistent with our previous in vitro results, the large PAS-containing fragment (PER 233-685) dimerized well in this assay (Fig. 2A). Reporter gene activation was dependent on PER interaction, because PER 233-685/LexA with the prey vector alone did not produce any de- tectable $\beta$-galactosidase. The $\operatorname{per}^{s}$ mutation, a serine to asparagine substitution at position 589 that shortens the circadian period from 24 to 19 hours $(3,14,16)$, dimerized as well (Fig. 2A). Surprisingly, the per $^{L}$ mutation also showed dimerization nearly indistinguishable from that of the wild-type (Fig. 2A), in contrast to our previous in vitro results that indicated a significant decrease in dimerization (12). Because the $\mathrm{per}^{L}$ mutation not only lengthens circadian period but also compromises temperature compensation $(4,6)$, we repeated the yeast assay at higher temperatures. $\mathrm{PER}^{\mathrm{L}}$ dimerization was essentially undetectable at $37^{\circ} \mathrm{C}$ (Fig. 2A), which indicates that some aspect of the interaction is temperature-sensitive.

To substantiate this correlation between circadian behavior in flies and dimerization in yeast, we made another nonconservative change at amino acid 243 (valine to arginine) (PER ${ }^{L} R$ ) and introduced this mutant per gene into flies by $\mathrm{P}$ element-mediated transformation (17). The two independent homozygote mutant lines showed lengthened and temperature-sensitive circadian periods that were very similar to those of the original per mutant (Table 1). We also compared the dimerization phenotype of $\mathrm{PER}^{\mathrm{L}} \mathrm{R}$ in yeast to that of $\mathrm{PER}^{\mathrm{L}}$ and of wild-type PER. By growth on a plate without Leu as well as by $\beta$-galactosidase activity measurements in liquid media, both the PER $^{\mathrm{L}} 233-685$ and PER ${ }^{\mathrm{L}} \mathrm{R} 233-685$ bait led to similar decreases in dimerization that were also sensitive to temperature (Table 2). When the preys also carried the same point mutations, dimerization was further reduced and even more sensitive to temperature.

To determine whether the temperature sensitivity of $\mathrm{PER}^{\mathrm{L}}$ dimerization might be peculiar to the yeast system, we also tested $\mathrm{PER}^{\mathrm{L}}$ dimerization in an in vitro chemical crosslinking and immunoprecipitation assay. PER 233-685/H [which carries a hem-
Fig. 1. The basic helix-loop-helix (bHLH) PAS proteins (SIM, AHR, and ARNT) and the full-length PER protein. The bHLH motif, PAS domain, the two 51amino acid PAS repeats, and the glutamine-rich (Q-rich) region are indicated. The asterisk indicates the $p e r^{L}$ and pers missense mutations. Numbers represent the first and last amino acids of the PER protein fragments. The C-domain is PER 524-685. The shaded box within the C-domain indicates the highly conserved region between fly PER and moth PER (21). 
Fig. 2. (A) $P E R^{L}$ dimerization is temperature-sensitive in the yeast two-hybrid system. Wild-type and mutant PER 233-685 baits and wild-type PER 233-685 or control preys were introduced into the yeast strain EGY48-pSH1834 $(15,26)$. Transformants were streaked onto a Ura-His-Trpglucose plate. They were then replica-plated onto two Ura-His-Trp $2 \%$ galactose-1\% raffinose plates containing $\mathrm{X}$-gal and incubated either at $30^{\circ} \mathrm{C}$ or $37^{\circ} \mathrm{C}$ overnight. (B) PER dimerization is temperature-sensitive in vitro. In vitro translations of the ${ }^{35}$ S-labeled wild-type $(W T)$ (lanes $1,2,7$, and 8), $\operatorname{per}^{L}$ (lanes 3, 4, 9, and 10), or per ${ }^{L} R$ (lane $5,6,11$, and 12) versions of PER 233-685/H were incubated at either $16^{\circ} \mathrm{C}$ or $25^{\circ} \mathrm{C}$ for 2 hours. They were further incubated at the same temperature either in the presence $(+)$ or the absence $(-)$ of $0.005 \%$ glutaraldehyde (GA) in phosphate buffer $(\mathrm{pH} \mathrm{7.4)}$ for $30 \mathrm{~min}$. They were then immunoprecipitated with antibody to $\mathrm{HA}$ and analyzed on a $10 \%$ SDS-polyacrylamide gel (30). The arrowhead on the left indicates the crosslinked homodimers. The doublet probably reflects crosslinking at two different locations, giving rise to different covalent dimers with different cross-sectional areas. In this gel, wild-type PER $233-685 / \mathrm{H}$ appears to give rise to more dimers at $16^{\circ} \mathrm{C}$ (lane 2) than at $25^{\circ} \mathrm{C}$ (lane 8). This is due to higher local background in lane 2 and was not seen in other experiments. PER ${ }^{L} 233-685 / H$ migrates more slowly on SDS-PAGE, as described (12).

agglutinin (HA) epitope at its $\mathrm{COOH}$-terminus] dimerized well and with nearly identical efficiencies at $16^{\circ} \mathrm{C}, 25^{\circ} \mathrm{C}$, and $30^{\circ} \mathrm{C}$ (Fig. 2B) (12). Consistent with the yeast two-hybrid data, PER $^{\mathrm{L}} 233-685 / \mathrm{H}$ in vitro dimerization was temperature-sensitive: it was undetectable at $30^{\circ} \mathrm{C}(12)$ and at $25^{\circ} \mathrm{C}$ but was detectable (albeit poorly) at $16^{\circ} \mathrm{C}$ (Fig. 2B). PER ${ }^{\mathrm{L} R}$ 233-685/H dimerization was undetectable at all three temperatures.

To examine whether the temperature dependence of dimerization was due to a detectable change in PER stability in yeast, we assayed amounts of PER by protein immunoblot. The results showed that amounts of mutant and wild-type PER were indistinguishable from each other and were inde-

Table 1. The period length of per ${ }^{L} R$ is sensitive to temperature (17). Periods were measured as described (27). CS, Canton S strain.

\begin{tabular}{|c|c|c|}
\hline Genotype & $\begin{array}{l}\text { Period } \\
( \pm \text { SEM) } \\
\text { (hours) }\end{array}$ & $\begin{array}{l}\text { Flies } \\
\text { tested } \\
(n)\end{array}$ \\
\hline \multicolumn{3}{|c|}{$18^{\circ} \mathrm{C}$} \\
\hline CS & $23.8 \pm 0.2$ & 11 \\
\hline per ${ }^{\mathrm{L}}$ & $27.1 \pm 0.1$ & 12 \\
\hline per ${ }^{\llcorner} R-25$ & $26.7 \pm 0.3$ & 6 \\
\hline per ${ }^{\mathrm{L}} R-27$ & $27.4 \pm 0.4$ & 6 \\
\hline \multicolumn{3}{|c|}{$25^{\circ} \mathrm{C}$} \\
\hline CS & $24.3 \pm 0.1$ & 15 \\
\hline$p e r^{\mathrm{L}}$ & $29.6 \pm 0.1$ & 11 \\
\hline per ${ }^{\mathrm{L}} R-25$ & $28.7 \pm 0.4$ & 7 \\
\hline per ${ }^{L} R-27$ & $28.6 \pm 0.3$ & 8 \\
\hline \multicolumn{3}{|c|}{$29^{\circ} \mathrm{C}$} \\
\hline CS & $24.2 \pm 0.1$ & 11 \\
\hline per ${ }^{\mathrm{L}}$ & $31.4 \pm 0.3$ & 10 \\
\hline $\operatorname{per}^{\mathrm{L}} R-25$ & $30.3 \pm 0.3$ & 12 \\
\hline per ${ }^{\llcorner} R-27$ & $30.1 \pm 0.2$ & 8 \\
\hline
\end{tabular}
To understand further the strong effect of the substitutions at amino acid 243, we
A

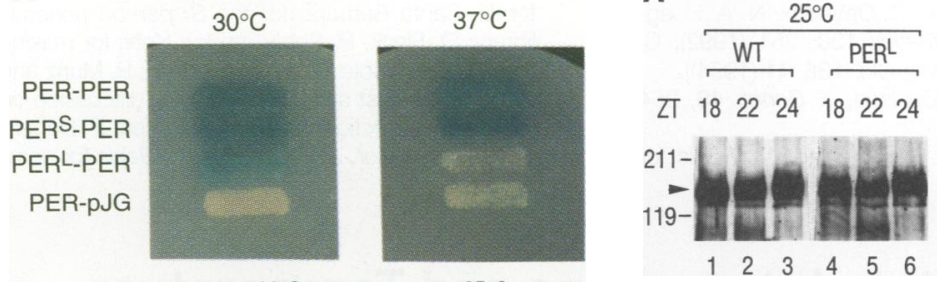

B

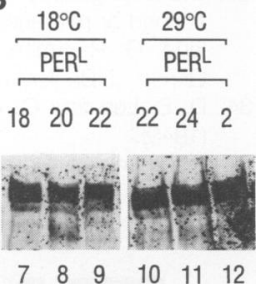

Fig. 3. The amount of $P E R^{L}$ protein in adult heads is similar to that of the wild-type protein (A) and is not affected by temperature (B). Wild-type (WT) or per $^{L}$ (PER ${ }^{L}$ ) flies were entrained with three cycles of light and dark at the indicated temperatures and frozen at the indicated times. Total head extracts were prepared and analyzed for PER by protein immunoblotting with antibodies to PER (31). The zeitgeber time (ZT; in hours) of fly collection is shown. The arrowhead indicates the PER protein band.

tested interactions between PER 233-390 (which contains only part of the PAS doso main, including amino acid 243 and the first PAS repeat) and the entire PER 233-है 685 fragment. This interaction was evend stronger than PER 233-685 homodimeriza $\mathrm{N}$ tion (Table 3), which raised the possibility that sequences on the $\mathrm{COOH}$-terminal side of the first PAS repeat (or COOH-termina? to PAS) may suppress PAS-mediated; dimerization through an intramolecular in teraction or by binding to a heterologouso cellular protein. We tested the first possibility with the yeast two-hybrid assay. $A \frac{\omega}{U}$ domain $\mathrm{COOH}$-terminal to PAS (PERe? 524-685, here termed the C-domain) asso ciated with PER 233-390 (Table 3), which suggests that an intramolecular interactione may contribute to PER function. We veri은 fied this interaction in the in vitro assay and also examined the effects of the per $\frac{\mathbb{d}}{8}$ mutations as well as those of temperature (Fig. 4A). Although only about $0.4 \%$ o PER 524-685/H (the PER 524-685 frago ment with an HA epitope at its $\mathrm{COOH}=$ terminus) associated with PER 233-390 at $16^{\circ} \mathrm{C}$, an intramolecular interaction might be expected to be weak when tested in an

Table 2. $P E R^{L}$ dimerization is temperature-sensitive in the yeast two-hybrid system. Plasmids that direct the synthesis of the listed bait and prey proteins were introduced into EGY48. The background refers to $\beta$-galactosidase activity when PER 233-685 bait was introduced with the prey vector pJG4-5. All interactions are presented as the percentage of the PER 233-685 homotypic interactions at $30^{\circ} \mathrm{C}$. Three independent isolates were tested for each interaction, and the average value is given here.

\begin{tabular}{|c|c|c|c|c|c|c|c|}
\hline \multirow{3}{*}{ Bait } & \multirow{3}{*}{ Prey } & \multicolumn{6}{|c|}{ Extent of dimerization at } \\
\hline & & \multicolumn{2}{|c|}{$25^{\circ} \mathrm{C}$} & \multicolumn{2}{|c|}{$30^{\circ} \mathrm{C}$} & \multicolumn{2}{|c|}{$37^{\circ} \mathrm{C}$} \\
\hline & & Leu & $\beta$-gal (\%) & Leu & $\beta$-gal (\%) & Leu & $\beta$-gal (\%) \\
\hline $\begin{array}{l}\text { PER 233-685 } \\
\text { PER' 233-685 } \\
\text { PER 233-685 } \\
\text { PER } 232 \text { 233-685 } \\
\text { PER'R 233-685 }\end{array}$ & $\begin{array}{l}\text { PER 233-685 } \\
\text { PER 233-685 } \\
\text { PER' 233-685 } \\
\text { PER 233-685 } \\
\text { PER'R 233-685 }\end{array}$ & $\begin{array}{l}+++ \\
+++ \\
++ \\
++ \\
++\end{array}$ & $\begin{array}{c}109 \pm 11 \\
59 \pm 9 \\
43 \pm 9 \\
34 \pm 5 \\
26 \pm 3\end{array}$ & $\begin{array}{c}+++ \\
++ \\
- \\
++ \\
-\end{array}$ & $\begin{aligned} & 100 \\
& 39 \pm 6 \\
& 6 \pm 2 \\
& 18 \pm 3 \\
& 8 \pm 1\end{aligned}$ & $\begin{array}{c}+++ \\
- \\
- \\
- \\
-\end{array}$ & $\begin{aligned} 112 & \pm 10 \\
12 & \pm 2 \\
4 & \pm 2 \\
7 & \pm 2 \\
8 & \pm 2\end{aligned}$ \\
\hline
\end{tabular}


Fig. 4. PAS-mediated inter- and intramolecular interactions in vitro. (A) per $^{L}$ enhances PAS-C-domain interactions. Wild-type and mutant versions of PER 233-390 fragments were translated in vitro and mixed with in vitrotranslated PER $524-685 / \mathrm{H}$ in a molar ratio of approximately $5: 1$ at the indicated temperature for 2 hours (PER 524-685/H and PER 233-390 contain the same number of methionine residues; thus, the ratio of their ${ }^{35} \mathrm{~S}$ label reflects the molar ratio). Single or mixed translation products were analyzed by 15\% SDS-PAGE either directly (lanes 1 to 3) or after immunoprecipitation with antibody to HA (lanes 4 to 13) (27). The positions of PER 524-685/H (30 kD; upper right arrowheads) and different versions of PER 233-390 (about 16 kD; lower right arrowheads) are indicated. Molecular weight standards are shown to the left. For unknown reasons, PER $524-685 / \mathrm{H}$ migrates much slower than its predicted molecular size (19 $\mathrm{kD}$ ) on SDS-PAGE. The approximately $13-\mathrm{kD}$ band in lanes 7 to 13 (just below PER 233-390) is probably a partial product of PER $524-685 / \mathrm{H}$. PER

A

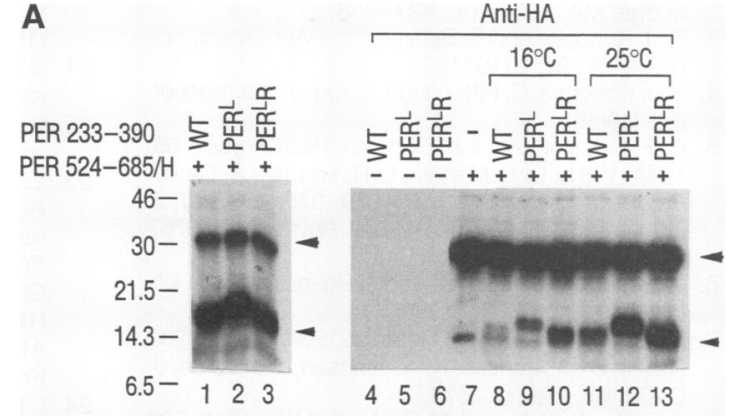

Anti-HA $16^{\circ} \mathrm{C} \quad 25^{\circ} \mathrm{C}$

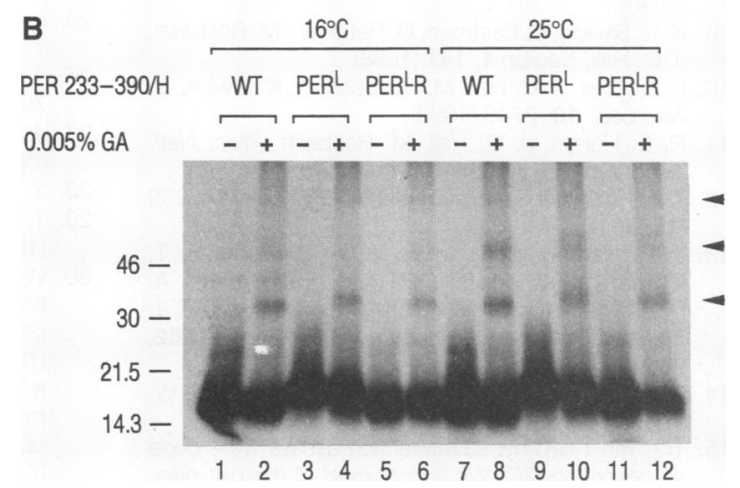

233-390 migrates slower than PER 233-390, most likely because of a conformational change (12). (B) per ${ }^{L}$ does not affect PAS self-association. In vitro translations of ${ }^{35}$ S-labeled wild-type (lanes $1,2,7$, and 8), per $^{L}$ (lanes 3, 4, 9, and 10), and per ${ }^{L} R$ (lane 5, 6, 11, and 12) versions of PER 233-390/H were incubated at either $16^{\circ} \mathrm{C}$ or $25^{\circ} \mathrm{C}$ for $30 \mathrm{~min}$. They were further incubated at the same temperature either in the presence $(+)$ or the absence $(-)$ of $0.005 \%$ glutaraldehyde in phosphate buffer $(\mathrm{pH} 7.4)$ for $30 \mathrm{~min}$. They were then immunoprecipitated with antibody to $\mathrm{HA}$ and analyzed on a $15 \%$ SDS-polyacrylamide gel (30). The arrowheads on the right indicate the cross-linked oligomers of the wild-type, per ${ }^{L}$, or $p^{2} r^{L} R$ versions of PER 233-390/H. Minor differences between the wild-type and per ${ }^{L}$ versions were not reproducible.

intermolecular assay. The $\mathrm{PER}^{\mathrm{L}}$ mutation led to a fourfold increase in the association of PER 233-390 with PER 524-685/H (Fig. $4 \mathrm{~A}$, lanes 8 and 9$)$. In addition, the interactions between the C-domain and the wild-type, the per ${ }^{L}$, and the $\operatorname{per}^{L} R$ versions of PER 233-390 all increased at $25^{\circ} \mathrm{C}$ (Fig. $4 \mathrm{~A}$, compare lanes 8 and 11 , lanes 9 and 12 , and lanes 10 and 13). In the cases of wildtype and $\operatorname{per}^{L}$, the increases were fourfold
$(3.8 \pm 0.4)$ and sixfold $(5.7 \pm 1.0)$, respectively (numbers are averaged from three experiments). Therefore, the per ${ }^{\mathrm{L}}$ mutation also increased the temperature coefficient of the interaction. In contrast, the per $\mathrm{pu}^{\mathrm{m}}$ tation in PER 524-685/H had no effectthat is, it was indistinguishable from the wild-type fragment (18). The increase in the PAS-C-domain interaction by the per $^{L}$ mutation indicates a direct association be-
Fig. 5. (A) A hypothetical equilibrium between the PER closed monomer, the open monomer, and the dimer. The PAS domain, C-domain, and $p e r^{L}$ mutation are indicated. A putative PAS-containing protein is shown to dimerize with PER. TIM, putative timeless protein. (B) A model for PER PAS-mediated intraand intermolecular interactions that may underlie temperature-compensated PER dimerization. "Concentration" refers to the hypothetical concentration of PAS-only dimers (PAS-PAS), PER monomers (PAS-C-domain), and PER dimers (PER-PER); it is an indication of the relative interaction strength.

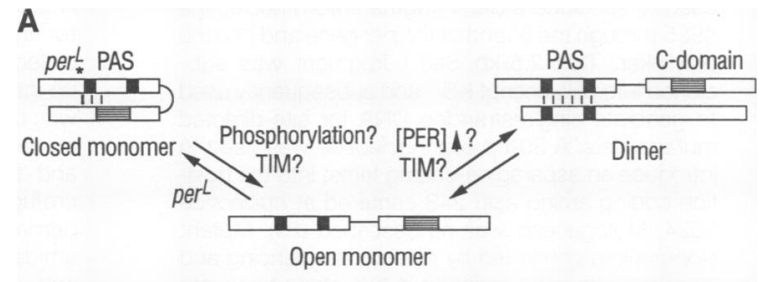

B

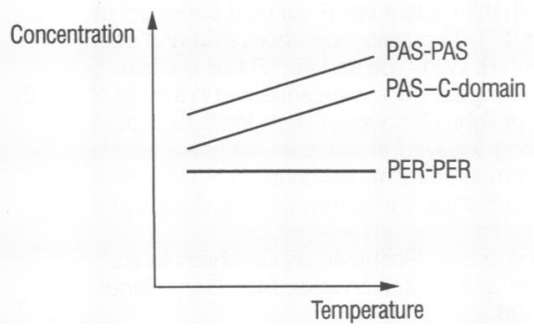

Table 3. The C-domain interacts with PAS in yeast. Assays were performed at $30^{\circ} \mathrm{C}$ on three independent isolates for each combination. $\mathrm{Val}$ ues shown are the average of the three individual values, which varied by less than $10 \%$. $\beta$-Gal activity represents the activation above background (expressed in fold increase). Background is the $\beta$-galactosidase activity of PER 233-685 paired with prey vector pJG4 -5 .

\begin{tabular}{|c|c|c|c|}
\hline \multirow[b]{2}{*}{ Bait } & \multirow[b]{2}{*}{ Prey } & \multicolumn{2}{|c|}{$\begin{array}{l}\text { C-domain } \\
\text { interaction }\end{array}$} \\
\hline & & Leu & $\begin{array}{c}\beta \text {-gal } \\
\text { activity } \\
\text { (fold } \\
\text { activa- } \\
\text { tion) }\end{array}$ \\
\hline $\begin{array}{l}\text { PER 233-685 } \\
\text { PERS 233-685 } \\
\text { PER 233-390 } \\
\text { PER 233-390 } \\
\text { PER 233-390 } \\
\text { PER 233-390 }\end{array}$ & $\begin{array}{l}\text { PER 233-685 } \\
\text { PER 233-685 } \\
\text { PER 233-685 } \\
\text { PER 361-501 } \\
\text { PER 451-685 } \\
\text { PER 524-685 }\end{array}$ & $\begin{array}{c}+++ \\
+++ \\
++++ \\
- \\
+ \\
+\end{array}$ & $\begin{array}{r}68.9 \\
70.4 \\
85.6 \\
1.4 \\
10.8 \\
12.4\end{array}$ \\
\hline
\end{tabular}

tween the two fragments.

To determine whether the eer $^{L}$ mutation also decreases intermolecular interactions in the absence of the C-domain, we performed chemical crosslinking and immunoprecipitation experiments with the short PER 233390/H fragment (Fig. 4B). As expected, wild-type PER 233-390/H underwent selfassociation. This interaction increased about threefold at higher temperatures $\left(25^{\circ} \mathrm{C}\right.$ as compared to $16^{\circ} \mathrm{C}$ ). In contrast to its strong negative effect on dimerization of the large PER 233-685 fragment (12), the per ${ }^{L}$ mutation had little effect on PER 233-390/H self-association at either temperature. A larger PER fragment (PER 233-485) containing the complete PAS domain interacted even more efficiently in this assay and resulted predominantly in higher molecular weight oligomers, but the $\operatorname{per}^{L}$ mutation also had no effect on these interactions (18). Taken together with the effect of PER ${ }^{\mathrm{L}}$ on the PAS-C-domain interaction, these data suggest that the $\operatorname{per}^{L}$ mutation may decrease PER 233-685 dimerization by increasing the strength of an inhibitory intramolecular interaction between the PER 233-390 and the PER 524-685 regions.

Our study reveals that per $^{L}$ point mutations render temperature-sensitive the homotypic interactions of a large PAS-containing fragment. In addition, our results show that a subregion of the PER PAS domain can associate with another region of PER (the C-domain) both in vitro and in yeast. This interaction is stronger at higher temperatures. The $\mathrm{per}^{\mathrm{L}}$ mutations increase the PAS$\mathrm{C}$-domain interaction and its temperature coefficient, with little or no effect on selfassociation of fragments that contain only PAS. We consider it unlikely that the PASC-domain interaction reflects only an inter- 
molecular interaction that contributes positively to PER 233-685 dimerization. This is because PER $^{\mathrm{L}}$ increases the PAS-C-domain interaction, which would then increase rather than decrease PER 233-685 dimerization. An important role for the C-domain is also indicated by its high degree of phylogenetic conservation (21).

We propose that the PER PAS domain not only engages in intermolecular interactions but also undergoes an intramolecular interaction with the C-domain (Fig. 5A). The intramolecular interaction would favor a "closed" conformation and would compete with PAS-mediated intermolecular associations. Because both sets of interactions share one or more components, they may change with temperature in a similar fashion; as a consequence, PER dimerization should manifest temperature compensation (Fig. 5B). The per ${ }^{L}$ mutation interferes with this balance as it enhances the intramolecular interaction as well as its temperature coefficient with little effect on PAS-delimited homotypic interactions. The $\mathrm{per}^{L}$ mutation may thus give rise to two different temperature coefficients for the two competing reactions, resulting in temperaturesensitive $\mathrm{PER}^{\mathrm{L}}$ intermolecular interactions. A conformational switch also helps to explain how a single amino acid substitution in a large fragment (PER 233-685) has such a strong effect on dimerization.

Our proposed intramolecular interaction might contribute to the gating of molecular events during the circadian cycle. This likely includes nuclear translocation; the per $^{L}$ mutation results in temperature-sensitive nuclear entry, which is correlated with its effects on circadian period (22). A similar role for an intramolecular interaction in the regulation of protein oligomerization or nuclear entry has been reported for several transcription factors (23). An intramolecular interaction should be independent of concentration and thus should predominate at low PER concentrations early in the accumulation cycle. PER phosphorylation (24) and the timeless gene product (25) may also affect a competition between intra- and intermolecular interactions (Fig. 5A). Although this model is unlikely to explain all aspects of temperature compensation (6), it suggests that a temperature-compensated activity could derive from two antagonistic protein-protein interactions (one intermolecular, the other intramolecular), each with a similar temperature coefficient.

\section{REFERENCES AND NOTES}

1. C. S. Pittendrigh, Proc. Natl. Acad. Sci. U.S.A. 40 1018 (1954); J. W. Hastings and B. M. Sweeney, ibid. 43, 804 (1957)

2. P. Lakin-Thomas, G. G. Coté, S. Brody, Crit. Rev. Microbiol. 17, 365 (1990); C. S. Pittendrigh, in Neurosciences: Third Study Program, F. O. Schmitt and F. G. Worden, Eds. (MIT Press, Cam- bridge, MA, 1974), pp. 437-458.

3. R. J. Konopka and S. Benzer, Proc. Natl. Acad. Sci U.S.A. 68, 2112 (1971).

4. R. J. Konopka, C. Pittendrigh, D. Orr, J. Neurogenet. 6, 1 (1989).

5. G. F. Gardner and J. F. Feldman, Plant Physiol. 68 1244 (1981); D. L. Mattern, L. R. Forman, S. Brody, Proc. Natl. Acad. Sci. U.S.A. 79, 825 (1982); J. J. Lorosa and J. F. Feldman, J. Biol. Rhythms 1, 18767 (1986).

6. J. Ewer, M. Hamblen-Coyle, M. Rosbash, J. C. Hall, J. Neurogenet. 7, 31 (1990)

7. I. Edery, J. E. Rutila, M. Rosbash, Science 263, 237 (1994); B. D. Aronson, K. A. Johnson, J. J. Loros, J. C. Dunlap, ibid., p. 1578.

8. P. E. Hardin, J. C. Hall, M. Rosbash, Nature 343, 536 (1990).

9. K. K. Siwicki, C. Eastman, G. Petersen, M. Rosbash J. C. Hall, Neuron 1, 141 (1988)

10. D. M. Zerr, J. C. Hall, M. Rosbash, K. K. Siwicki, J. Neurosci. 10, 2749 (1990).

11. P. E. Hardin, J. C. Hall, M. Rosbash, Proc. Natl. Acad. Sci. U.S.A. 89, 11711 (1992).

12. Z. J. Huang, I. Edery, M. Rosbash, Nature 364, 259 (1993).

13. J. R. Nambu, J. O. Lewis, K. A. Wharton, S. T. Crews, Cell 67, 1157 (1991); K. M. Burbach, A Poland, C. A. Bradfield, Proc. Natl. Acad. Sci. U.S.A 89, 8185 (1992); E. C. Hoffman et al. Science 252. 954 (1991)

14. M. K. Baylies, T. A. Bargiello, F. R. Jackson, M. W Young, Nature 326, 390 (1987)

15. The yeast two-hybrid interaction assays were done as described (26). We constructed all the bait plasmids by inserting complementary DNAs (cDNAs) coding for different PER fragments in-frame downstream of the lexA gene in plasmid plexA202+PL (26). We constructed all the prey plasmids by inserting the same cDNAs in-frame downstream of the activation domain in plasmid pJG4-5. Each pair of bait and prey plasmid was introduced into the yeast host strain EGY48(Mata, trp1 ura3 his3 LEU2: plexop6-LEU2) for the interaction experiments. The lac $\mathrm{Z}$ reporter used was $\mathrm{pSH} 18-34$. The interactions between bait and prey peptides were detected as the activation of either of the two reporter genes: LEU2 as growth in the absence of leucine and $\beta$-galactosidase as blue color on $x$-gal plates. The liquid $\beta$-galactosidase assay was performed as described (26). Expression of bait and prey fusion proteins was monitored by protein immunoblotting with LexA and HA antibodies.

16. Q. Yu et al., Proc. Natl. Acad. Sci. U.S.A. 84, 784 (1987)

17. To create the $p e r^{L} R$ mutation for germline transformation, we used a subclone of the per gene for mutagenesis from a 13.2-kb per genomic fragment coding an $\mathrm{HA}$ tag at the $\mathrm{COOH}$-terminus cloned into cp20.1 (27). An Xba I fragment extending from nucleotide 2445 [numbering is as in (28)] in this clone through the $3^{\prime}$ end of the per gene (including some cp20.1 sequences) was subcloned into pBluescript $\mathrm{KS}^{-}$. Clones of one orientation were chosen and used to subclone a Sac I fragment from nucleotide 4935 through the $3^{\prime}$ end of the per gene and into the polylinker. This $2.5-\mathrm{kb}$ Sac I fragment was subcloned into pBluescript $\mathrm{KS}^{-}$and subsequently used to generate single-stranded DNA for site-directed mutagenesis. A 30-bp oligonucleotide was used to introduce an asparagine-coding triplet into the position coding amino acid 243 centered at nucleotide 3624. Mutagenesis was as described (29). Mutant clones were confirmed by dideoxy sequencing and were subsequently recloned in two steps back into the starting vector. The $p e r^{01} ; y^{506}$ flies were transformed with the mutant per P-element construct as described (27). Two lines were recovered and designated $\operatorname{per}^{L} R$. Wild-type and $p e r^{L} R$ flies containing one copy of the per gene were entrained in a cycle of 12 hours of light: 12 hours of dark for 2 to 3 days before being assayed in constant darkness at the indicated temperatures as described (27). Data were collected for 5 days, and activity periods determined by $\chi$ square periodogram analysis (27).

18. Z. J. Huang and M. Rosbash, unpublished results.

19. R. F. Smith and R. J. Konopka, Mol. Gen. Genet. 189,30 (1982)
20. G. G. Coté and S. Brody, J. Theor. Biol 121, 487 (1986).

21. S. M. Reppert, T. Tsai, A. L. Roca, I. Sauman, Neuron 13, 1167 (1994)

22. K. Curtin, Z. J. Huang, M. Rosbash, ibid. in press.

23. E. S. Klein, D. M. Simmons, L. W. Swanson, M. G. Rosenfeld, Genes Dev. 7, 55 (1993); S. K. Rabindran, R. I. Haroun, J. Clos, J. Wisniewski, C. Wu Science 259, 230 (1993); H.-C. Liou, G. P. Nolan, S. Ghosh, T. Fujita, D. Baltimore, EMBO J. 11, 3003 (1992); V. Blank, P. Kourilsky, A. Israël, ibid. 10, 4159 (1991); F. C. De La Brousse and S. L. McKnight, Trends Genet. 9, 151 (1993).

24. I. Edery, L. J. Zwiebel, M. E. Dembinska, M. Rosbash, Proc. Natl. Acad. Sci. U.S.A. 91, 2260 (1994).

25. L. B. Vosshall, J. L. Price, A. Sehgal, L. Saez, M. W. Young, Science 263, 1606 (1994).

26. J. Gyuris, E. Golemis, H. Chertkov, R. Brent, Cell 75 , 791 (1993)

27. J. E. Rutila, I. Edery, J. C. Hall, M. Rosbash, J. Neurogenet. 8, 101 (1992).

28. Y. Citri et al., Nature 326, 42 (1987)

29. T. A. Kunkel, Proc. Natl. Acad. Sci. U.S.A. 82, 488 (1985).

30. We generated cDNA templates for in vitro transcription and translation by the polymerase chain reaction (PCR) from the full-length per cDNA [pSP65ATper (12)] and gel-purified them. The 5 ' primers contained $c$ a T7 promoter, the 5' leader and ATG from the human $\beta$-globin gene (12), and the corresponding per cDNA sequences; the $3^{\prime}$ primer contained, from $5^{\prime}$ to 3', a TAG stop codon, the sequence corresponding to the HA peptide YYPYDVPDVASL; abbreviations for 4

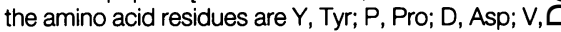
Val; A, Ala; S, Ser; and L, Leu (12)], and correspond- $c$ ing per cDNA. Coupled in vitro transcription and $O$ translation were performed with rabbit reticulocyte lysate in the presence of ${ }^{35} \mathrm{~S}$-labeled methionine ac- 0 . cording to the manufacturer's instructions (TNT, Pro- $O$ mega). Immunoprecipitation was essentially as de- ช্ scribed (12), except that the HND buffer contained $\frac{\varepsilon}{d}$ $0.1 \%$ NP-40. For chemical crosslinking, $2 \mu \mathrm{l}$ of the 0 above translation reaction was incubated in $30 \mu$ of $0.1 \mathrm{M}$ phosphate buffer $(\mathrm{pH} 7.4)$ and glutaraldehyde $\frac{}{\mathrm{C}}$ at different temperatures for the indicated times. We terminated the crosslinking by adding $2 \mathrm{M}$ tris $\mathrm{pH}$ 7.5 ) to a final concentration of $100 \mathrm{mM}$. Samples were diluted in $250 \mu$ of modified HND buffer as above. Subsequent immunoprecipitation procedures $\varepsilon$ were as described (12).

31. Flies were entrained with three cycles of 12 hours of light: 12 hours of dark, collected at the indicated times, and frozen at $-80^{\circ} \mathrm{C}$. Protein extract was made from 20 heads for each time point as described (24), with minor modifications. Each- 음 sample was homogenized in $20 \mu$ l of ice-cold extraction buffer [20 mM Hepes, $\mathrm{pH} 7.5,100 \mathrm{mM}$ $\mathrm{KCl}, 10 \%$ glycerol, $50 \mathrm{mM} \mathrm{NaF}, 10 \mathrm{mM}$ EDTA, 10 $\mathrm{mM}$ dithiothreitol, $0.1 \%$ Triton $\mathrm{X}-100,0.5 \mathrm{mM}$ phenylmethylsulfonyl fluoride, aprotinin $(20 \mu \mathrm{g} / \mathrm{ml})$, leupeptin $(5 \mu \mathrm{g} / \mathrm{ml})$, and pepstatin $(5 \mu \mathrm{g} / \mathrm{ml})$ ] Another $10 \mu \mathrm{l}$ of extraction buffer was then used to rinse the tip of the homogenizer, then was collected and combined with the extract. Because no internal control was included in the assay, care was taken not to lose any protein from the starting material. We added $10 \mu$ of $4 \times$ SDS sample buffer and the sample was boiled for $5 \mathrm{~min}$ and $\mathrm{mi}$ crofuged to pellet the undissolved debris. The su pernatant was loaded on a $5.7 \%$ SDS-polyacrylamide gel electrophoresis (SDS-PAGE) gel. Protein immunoblotting was done as described (24). For quantitation of the chemiluminescence (ECL, Amersham), the blot was exposed to a chemilumines cence screen (Bio-Rad) for 0.5 to 3 hours and quantified in a Bio-Rad phosphorimager

32. We thank R. Finley and R. Brent for DNA plasmids and yeast strains and $M$. Dembinska for help with the protein immunoblotting experiments. We are gratefu for I. Edery, U. Schibler, and C. Pikielny for comments on the manuscript and $L$. A. Monaghan for excellent secretarial assistance. Supported in part by a grant from NIH to M.R. (GM-33205).

16 August 1994; accepted 2 December 1994 